\title{
Estimated Rate of Prostacyclin Secretion into the Circulation of Normal Man
}

\author{
Garret A. FitzGerald, Alan R. Brash, Pierre Falardeau, and John A. Oates, \\ Division of Clinical Pharmacology, Department of Pharmacology, Vanderbilt \\ University School of Medicine, Nashville, Tennessee 37232
}

A B S T RACT The rate of secretion of prostacyclin $\left(\mathrm{PGI}_{2}\right)$ into the circulation of normal man was estimated by measurement of the 2,3-dinor-6-keto- $\mathrm{PGF}_{1 \alpha}(\mathrm{D})$ and 15-keto-13,14-dihydro-2,3-dinor-6-keto-PGF ${ }_{1 \alpha}$ (KDD) urinary metabolites of $\mathrm{PGI}_{2}$. Subjects received 6-h intravenous infusions of vehicle alone and $\mathrm{PGI}_{2}$ at $0.1,0.4$, and $2.0 \mathrm{ng} / \mathrm{kg}$ per min in random order. The fractional elimination of the metabolites was independent of the rate of $\mathrm{PGI}_{2}$ infusion. $6.8 \pm 0.3 \%$ of the infused $\mathrm{PGI}_{2}$ appeared as D and $4.1 \pm 0.4 \%$ as KDD. The regression of infused $\mathrm{PGI}_{2}$ upon the quantities of the two metabolites excreted in excess of control values permitted estimation of the rate of entry of endogenous $\mathrm{PGI}_{2}$ into the circulation corresponding to a given quantity of metabolite excreted. Using the quantities excreted in the $24 \mathrm{~h}$ from commencement of the infusions the estimated rates were $0.08 \pm 0.02 \mathrm{ng} / \mathrm{kg}$ per min from $D$ and $0.10 \pm 0.03$ from KDD. Studies with exogenous $\mathrm{PGI}_{2}$ suggest that infusion rates of 2-4 $\mathrm{ng} /$ $\mathrm{kg}$ per min are required to achieve the threshold for inhibition of platelet function (ex vivo) in man. Although not precluding a role for $\mathrm{PGI}_{2}$ in local plateletvessel wall interactions, the much lower estimates obtained in this study suggest that endogenous $\mathrm{PGI}_{2}$ is unlikely to act as a circulating antiplatelet agent in healthy man.

\section{INTRODUCTION}

Prostacyclin $\left(\mathrm{PGI}_{2}\right)^{1}$ relaxes vascular smooth muscle (1) and potently inhibits platelet aggregation (2). Unlike other prostaglandins (3), $\mathrm{PGI}_{2}$ is not extensively metabolized by the lung (4) and has been proposed as a physiologically important hormone in vivo. Both Gryglewski et al. (5) and Moncada et al. (6) demonstrated

Dr. Falardeau's present address is Institut de Recherche Clinique de Montreal, Quebec.

Received for publication 1 April 1981 and in revised form 26 June 1981.

${ }^{1}$ Abbreviation used in this paper: $\mathrm{PGI}_{2}$, prostacyclin. that $\mathrm{PGI}_{2}$ binding antibodies cause a decrease in platelet aggregate deposition on superfused ex vivo tendons (7) in anaesthesized rabbits and cats. This effect was more marked in arterial than venous blood, suggesting the pulmonary generation of a systemically active, $\mathrm{PGI}_{2}$-like substance. However, other investigators using $\mathrm{PGI}_{2}$-binding antibodies failed to obtain evidence in support of this concept $(8-10)$. The present investigation was designed to estimate the rate of entry of endogenous $\mathrm{PGI}_{2}$ into the circulation in man. The results obtained suggest that $\mathrm{PGI}_{2}$ is not a physiologically important circulating antiplatelet hormone in normal man.

\section{METHODS}

Subjects and study design. Four male volunteers aged 25-45 yr were investigated. Their weight ranged from 68 to $76 \mathrm{~kg}$ and they abstained from all medication for $8 \mathrm{wk}$ before the study. All were Caucasian and nonsmokers. The protocol was approved by the Committee for the Protection of Human Subjects of Vanderbilt Medical School.

The subjects received 6-h intravenous infusions of vehicle alone (glycine buffer, $\mathrm{pH} 10.5$ ), and $\mathrm{PGI}_{2}$ at $0.1,0.4$, and 2.0 $\mathrm{ng} / \mathrm{kg}$ per min in random order. Low rates of infusion were chosen to minimize the likelihood of altering metabolism secondary to changes in organ-related blood flow. Infusions were separated by 6-d intervals. Urine was collected for determination of $\mathrm{PGI}_{2}$ metabolites in two hourly aliquots during and immediately after the infusion. The subjects were permitted a light breakfast on the morning of the investigation. The studies commenced at $1400 \mathrm{~h}$ and a snack was provided at $1700 \mathrm{~h}$. A collection of urine for $\mathrm{PGI}_{2}$ metabolites was obtained on a separate occasion during which the volunteers were ambulant.

Analytical methods. The rate of entry of endogenous prostacyclin into the circulation was estimated by quantification of the 2,3-dinor-6-keto-PGF $1 \alpha$ and the 15-keto-13,14dihydro-2,3-dinor-6-keto $\mathrm{PGF}_{1 \alpha}$ metabolites of $\mathrm{PGI}_{2}$ in urine. Stable isotope ratio methods were developed, using gaschromatography-mass spectrometry in the selected ion monitoring mode (11). Briefly, the initial step was synthesis of deuterium- and tritium-labeled 6-keto-PGF ${ }_{1 \alpha}$, which subsequently was converted to the metabolites. Deuterium was incorporated into positions 10 and 8 of $\mathrm{PGE}_{2}$ by exchange with deuterium-labeled carbitol, and the 9-ketone reduced to yield deuterated $\mathrm{PGF}_{2 \alpha}$. This was derivatized to 
the methyl ester and converted via the iodo-ether to $(8,10,10$ $\left.{ }^{2} \mathrm{H}_{3}\right)-\mathrm{PGF}_{2 \alpha}$. In a similar procedure, tritium was incorporated into the 9 position by the reduction of the deuterium-labeled $\mathrm{PGE}_{2}$ by sodium borotritiide. Recovery and identification of the metabolites was monitored by addition of deuteriumand tritium-labeled metabolites of 6-keto-PGF ${ }_{1 \alpha}$ to the urine before extraction, derivatization and gas-chromatographymass spectrometry.

Statistical analysis. Significance of the data was evaluated by Student's $t$ test. Owing to the inequality of variance in the metabolites excreted at different doses of $\mathrm{PGI}_{2}$, regression analysis was performed by a weighted least squares approach (12). Two-tailed probabilities were employed throughout the analysis. All values are expressed as the mean $\pm S E M$.

\section{RESULTS}

Blood pressure and heart rate were unchanged from control values during the $\mathrm{PGI}_{2}$ infusions. There was no significant difference between the total quantities of 2,3-dinor-6-keto- $P G F_{1 \alpha}(499.9 \pm 46$ ng vs. $374.9 \pm 80.2 \mathrm{ng}$; $P>0.10)$ and 15-keto-13,14-dihydro-2,3-dinor6-ketoPGF $_{1 \alpha}(229.1 \pm 33$ ng vs. $200.0 \pm 49$ ng; $P>0.10)$ excreted on the ambulant and infusion control days. The rates of excretion of the two metabolites during the collection periods on the infusion control day are illustrated in Table I. Metabolite excretion increased during the sequential 2-h collection periods within each $\mathrm{PGI}_{2}$ infusion (Fig. 1). The fractional elimination of the metabolites was independent of the rate of $\mathrm{PGI}_{2}$ infusion. A mean $6.8 \%$ of the infused $\mathrm{PGI}_{2}$ appeared as 2,3-dinor-6-keto-PGF $F_{1 \alpha}$ and a mean $4.1 \%$ as 15-keto13,14-dihydro-2,3-dinor-6-keto-PGF ${ }_{1 \alpha}$ (Table II).

Interpolation of metabolite values obtained on the control infusion day onto the linear relationship between the quantities of infused $\mathrm{PGI}_{2}$ and the amount of the metabolite excreted in excess of control values permitted calculation of the rate of entry of endogenous $\mathrm{PGI}_{2}$ into the circulation (Fig. 2). For these purposes, it was assumed that the linear relationship between the rate of $\mathrm{PGI}_{2}$ infused and the quantities of metabolites excreted existed for $\mathrm{PGI}_{2}$ below $0.1 \mathrm{~kg} / \mathrm{min}$. Although it would be logically expected that when the $\mathrm{Y}$ variable (infused $\mathrm{PGI}_{2}$ ) was zero the $\mathrm{X}$ variable (quantity of urinary metabolite excreted in excess of control values) would also be zero, the regression lines were tested against the hypothesis that the $\mathrm{Y}$ intercept was zero prior to forcing the lines through the origin (13). The regressions of infused $\mathrm{PGI}_{2}$ upon both the 2,3dinor-6-keto-PGF ${ }_{1 \alpha}(t=1.46 ; P>0.05)$ and the 15keto-13,14-dihydro-2,3-dinor-6-keto-PGF ${ }_{1 \alpha}(t=0.047$; $P>0.05)$ yielded estimates of the $\mathrm{Y}$ intercept which were not significantly different from zero.

Linear equations were obtained by regression of infused $\mathrm{PGI}_{2}$ upon the 24-h quantities of the metabolites excreted in excess of control values. Insertion of the quantities of the metabolites excreted during the 6-h control infusions into these equations permitted estimation of the rate of entry of endogenous
TABLE I

Urinary Metabolites of Prostacyclin: Control Values

\begin{tabular}{lcc}
\hline & $\begin{array}{c}\text { 2,3-dinor-6-keto } \\
\text { prostaglandin } F_{1 \alpha}\end{array}$ & $\begin{array}{c}\text { 15-keto-13,14-dihydro-2,3-dinor- } \\
\text { 6-keto-prostaglandin } F_{1 a}\end{array}$ \\
\hline & $p g / m g$ creatinine & pg/mg creatinine \\
Ambulant control, & & \\
24 h & $234.4 \pm 37.1$ & $138.4 \pm 36.5$ \\
& & \\
Control infusion & & \\
$0-2$ h & $243.2 \pm 55.1$ & $182.5 \pm 33.7$ \\
$2-4 \mathrm{~h}$ & $196.2 \pm 29.7$ & $163.3 \pm 54.8$ \\
$4-6 \mathrm{~h}$ & $266.7 \pm 68.7$ & $246.7 \pm 88.5$ \\
$6-18 \mathrm{~h}$ & $282.5 \pm 23.9$ & $93 \pm 39.4$ \\
$18-24 \mathrm{~h}$ & $314.9 \pm 106.8$ & $72.4 \pm 18.1$ \\
\hline
\end{tabular}

The excretion of the prostacyclin metabolites is expressed per milligram of creatinine excreted during the two control periods: (a) "ambulant" control, when a 24-h collection was performed while the subjects were otherwise unrestricted (b) infusion control, when the subjects received an intravenous infusion of vehicle alone (glycine buffer $\mathrm{pH}$ 10.5) from hours $0-6$, during which they lay supine and were thereafter unrestricted.

$\mathrm{PGI}_{2}$ into the circulation. The estimated rates were $0.08 \pm 0.02 \mathrm{ng} / \mathrm{kg}$ per min from the 2,3-dinor-6-keto-PGF ${ }_{1 \alpha}$ metabolite and $0.10 \pm 0.03 \mathrm{ng} / \mathrm{kg}$ per min from 15-keto13,14-dihydro-2,3-dinor-6-keto-PGF ${ }_{1 \alpha}$ (Table III).

Finally, these metabolites arise by enzymatic conversion from $\mathrm{PGI}_{2}$ or 6-keto- $\mathrm{PGF}_{1 \alpha}$ (14). The major portion of this enzymatic activity is thought to occur in the liver and kidney following the entry of $\mathrm{PGI}_{2}$ into the circulation. However, should some conversion occur within the organ of biosynthesis the value that we have obtained may slightly overestimate the rate of $\mathrm{PGI}_{2}$ secretion into the bloodstream.

\section{DISCUSSION}

We have estimated the rate of entry of endogenous $\mathrm{PGI}_{2}$ into the bloodstream by quantification of 2 major urinary metabolites of $\mathrm{PGI}_{2}$ in man $(14,15)$. Because $\mathrm{PGI}_{2}$ may have been converted in part to these metabolites prior to its entry into the circulation, the rates obtained represent maximal estimates. The mean value obtained using the 2,3-dinor-6-keto-PGF $1 \alpha$ metabolite $(0.08 \mathrm{ng} / \mathrm{kg}$ per min) was remarkably concordant with the estimate derived from the 15-keto13,14-dihydro-2,3-dinor-6-keto-PGF ${ }_{1 \alpha} \quad(0.10 \mathrm{ng} / \mathrm{kg}$ per min).

Studies with exogenous $\mathrm{PGI}_{2}$ suggest that infusion rates of 2-3 $\mathrm{ng} / \mathrm{kg}$ per min are required to achieve the threshold for either inhibition of platelet function ex vivo (16) or systemic hemodynamic effects in man (16, 17). Although the threshold antiplatelet effect of prostacyclin in vivo may be somewhat less than studies ex vivo suggest, the much lower estimates of the rate of 


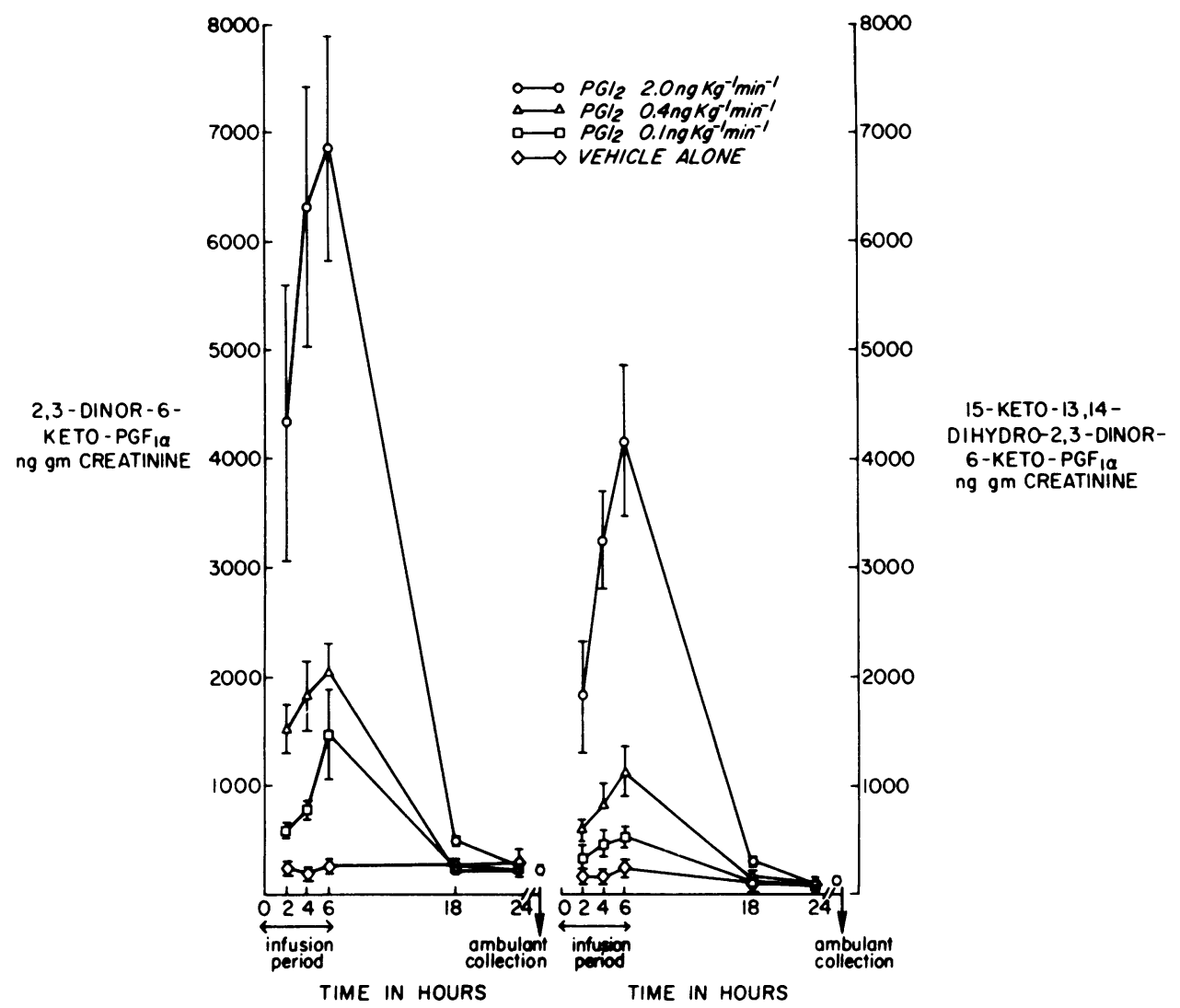

FIGURE 1 Changes in the rate of excretion of 2,3-dinor-6-keto-PGF $F_{1 \alpha}$ and 15-keto-13,14dihydro-2,3-dinor-6-keto-PGF ${ }_{1 \alpha}$ during and after 6-h infusions of $\mathrm{PGI}_{2}$ and vehicle (glycine buffer $\mathrm{pH}$ 10.5) alone. The quantity of the metabolite excreted during an unrestricted 24 -h collection (ambulant control) is also shown.

entry of endogenous $\mathrm{PGI}_{2}$ into the bloodstream suggest that it is unlikely to have a physiological role as a circulating hormone in man.

The suggestion that the lungs might act, not only as filters for unwanted vasoactive substances, but as

TABLE II

Percentage Conversion of Prostacyclin to Urinary Metabolites

\begin{tabular}{ccc}
\hline \multicolumn{3}{c}{ 24-h period from start of infusion } \\
\hline $\begin{array}{c}\text { Rate of } \text { PGI }_{2} \\
\text { infusion }\end{array}$ & $\begin{array}{c}\text { 2,3-dinor-6-keto } \\
\text { prostaglandin } F_{1 \alpha}\end{array}$ & $\begin{array}{c}\text { 15-keto-13,14-dihydro-2,3-dinor- } \\
\text { 6-keto-prostaglandin } F_{1 \alpha}\end{array}$ \\
\hline ng/kg per min & $\%$ & $\%$ \\
0.1 & $7.5 \pm 0.6$ & $4.0 \pm 1.2$ \\
0.4 & $6.6 \pm 1.4$ & $4.2 \pm 0.4$ \\
2.0 & $6.0 \pm 1.0$ & $2.9 \pm 0.6$ \\
$\begin{array}{c}\text { Mean of } 3 \\
\text { infusions }\end{array}$ & $6.8 \pm 0.3$ & $4.1 \pm 0.4$
\end{tabular}

The fractional conversion rate of infused $\mathrm{PGI}_{2}$ into the two metabolites is expressed for the 24-h period commencing with each infusion. Fractional conversion rates are also expressed for each individual's mean over the three rates of $\mathbf{P G I}_{2}$ infusion. generators of circulating hormones was supported by the observations of Gryglewski (5) and Moncada (6) and their colleagues. They demonstrated that exogenous $\mathrm{PGI}_{2}$ decreased superfused ex vivo tendon weight in heparinized, anesthetized rabbits and cats and that this effect was inhibited by infusion of an antiserum to a stable $\mathrm{PGI}_{2}$ analogue (5,6-dihydro- $\mathrm{PGI}_{2}$ ). Tendon weight gain, due to deposition of platelet aggregates (17) occurred in the absence of exogenous $\mathrm{PGI}_{2}$ and was enhanced by the additional $\mathrm{PGI}_{2}$ antibodies. This effect was more pronounced in arterial than venous blood, suggesting the pulmonary generation of a systemically active, $\mathbf{P G I}_{2}$-like substance. This proposal was further supported by the demonstration of an arterio-venous gradient of 6-keto-PGF ${ }_{1 \alpha_{1}}$, the hydration production of $\mathrm{PGI}_{2}$, in humans undergoing cardiac catheterization (18).

However, Smith et al. (8) failed to demonstrate an effect of infusion of $\mathrm{PGI}_{2}$-binding antibodies (to 6-keto$\mathrm{PGF}_{1 \alpha}$ ) on basal blood pressure in anesthetized cats even though the antiplatelet and vasodepressor response to a concomitant infusion of exogenous $\mathbf{P G I}_{2}$ could be inhibited. Steer et al. (9) found that addition of 


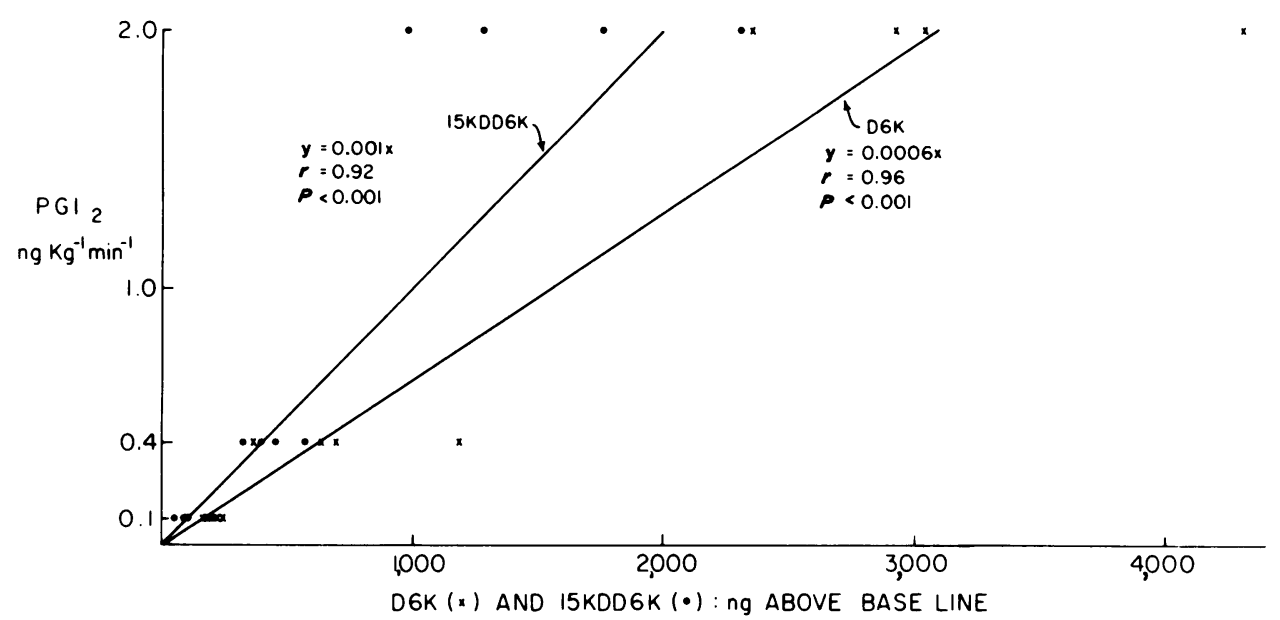

FIGURE 2 Infused $\mathrm{PGI}_{2}$ is regressed upon the quantities of two urinary metabolites, 2,3-dinor-

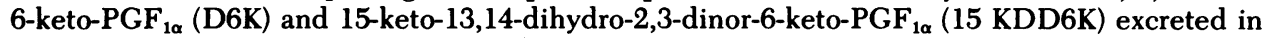
excess of control values during the infusion of vehicle (glycine buffer, $\mathrm{pH} \mathrm{10.5)}$ alone in four subjects. Insertion of the 6-h (corresponding to the duration of infusion) control value of D6K or $15 \mathrm{KDD} 6 \mathrm{~K}$ into the appropriate linear equation permits estimation of the rate of entry of endogenous $\mathrm{PGI}_{2}$ into the circulation (Table III). Having established that the Y-intercept did not differ significantly from zero, the linear regressions were constrained to pass through the origin.

$\mathrm{PGI}_{2}$ binding antibodies (to 5,6-dihydro- $\mathrm{PGI}_{2}$ ) to human platelet-rich plasma after either arterial or venous blood collection failed to alter platelet aggregation. Addition of these antibodies to platelet-rich plasma inhibited the effects of exogenous $\mathrm{PGI}_{2}$ on both aggregation and platelet cyclic AMP. Whereas these investigations suggested that $\mathbf{P G I}_{2}$ was unlikely to act as a physiologically important antiplatelet circulating agent, similar studies with antibodies to 5,6-dihydro$\mathrm{PGI}_{2}$ led Pace-Asiak and his colleagues (10) to conclude that $\mathrm{PGI}_{2}$ did not act as a systemic vasodepressor hormone in the normotensive or hypertensive rat.

Considerable controversy also exists as to the concentration of 6-keto-PGF ${ }_{1 \alpha}$ in human plasma. Estimates have ranged from $10-15 \mathrm{ng} / \mathrm{ml}$ using superfusion techniques (19) to $100-200 \mathrm{pg} / \mathrm{ml}$ using both radioimmunoassay (20) and gas chromatography-mass spectrometry (21). Recently the use of gas chromatographelectron capture methods suggests that "resting" levels may be much lower (22).

Myatt et al. (23) estimated the clearance rate of $\mathrm{PGI}_{2}$ in man by infusing exogenous $\mathrm{PGI}_{2}$ and measuring 6-keto-PGF ${ }_{1 \alpha}$ at pseudo-steady state. Because of concentrations of 6-keto-PGF ${ }_{1 \alpha}$ measured in the bloodstream represent a mixture of $\mathrm{PGI}_{2}$ and 6-keto-PGF ${ }_{1 \alpha}$, the clearance of $26.2 \pm 4.7 \mathrm{ml} / \mathrm{kg}$ per min that they obtained would tend to underestimate total plasma clearance of endogenous $\mathrm{PGI}_{2}$. Thus, a maximal estimate of the circulating concentration of $\mathrm{PGI}_{2}$ may be obtained by dividing the rate of entry of $\mathrm{PGI}_{2}$ into the bloodstream $(\sim 0.09 \mathrm{ng} / \mathrm{kg}$ per min) by this rate of plasma clearance $(\sim 26.2 \mathrm{ml} / \mathrm{kg}$ per min) resulting in $3.4 \mathrm{pg} / \mathrm{ml}$. This is an order of magnitude less than the

TABLE III

Estimated Rate of Entry of Endogenous $\mathrm{PGI}_{2}$ into the Circulation

\begin{tabular}{ccc}
\hline 2,3-dinor-6-keto-PGF & $\begin{array}{c}1 \alpha \\
\text { (D6K): } \\
\text { Control excretion } \\
\text { of D6K, ng }\end{array}$ & $\begin{array}{c}\text { Entry rate of } \text { PGI }_{2} \text {, } \\
\text { ng/kg per min }\end{array}$ \\
Subjects & 182.8 & \\
1 & 114.3 & 0.11 \\
2 & 72.1 & 0.07 \\
3 & 173.1 & 0.04 \\
4 & $135 \pm 26.0$ & 0.10 \\
Mean \pm SEM & & $0.08 \pm 0.02$
\end{tabular}

15-keto-13,14-dihydro-2,3-dinor-6-keto- $\mathrm{PGF}_{1 \alpha}$ (15KDD6K):

\begin{tabular}{ccc} 
Subjects & $\begin{array}{c}\text { Control excretion } \\
\text { of 15KDD6K, ng }\end{array}$ & $\begin{array}{c}\text { Entry rate of } \text { PGI }_{2}, \\
n g / k g \text { per min }\end{array}$ \\
1 & 74.0 & 0.07 \\
2 & 173.7 & 0.17 \\
3 & 116.1 & 0.12 \\
4 & 52.1 & 0.05 \\
\cline { 2 - 2 } \pm Mean & $104.0 \pm 26.8$ & $0.10 \pm 0.03$ \\
\hline
\end{tabular}

Total quantities of the two metabolites excreted on the "infusion" control day are expressed for the 6-h infusion period. The regression of the $\mathrm{PGI}_{2}$ infusion rate onto the quantities of the two metabolites excreted in excess of control values in the $24 \mathrm{~h}$ from the start of the infusion permit estimation of the rate of entry of endogenous $\mathrm{PGI}_{2}$ into the circulation for a given metabolite excretion (Fig. 2). 
threshold concentration of $\mathrm{PGI}_{2}$ required (9) to inhibit aggregation in vitro of platelets obtained from human volunteers $(36 \mathrm{pg} / \mathrm{ml})$. The threshold for patients with peripheral vascular disease has been reported (24) to be much higher $(1,500 \mathrm{pg} / \mathrm{ml})$.

In conclusion, we have measured the excretion of two urinary $\mathrm{PGI}_{2}$ metabolites during the infusion of exogenous $\mathrm{PGI}_{2}$ over a 20 -fold dose range to enable estimation of the rate of entry of endogenous $\mathrm{PGI}_{2}$ into the bloodstream. Our results do not preclude an important role for $\mathrm{PGI}_{2}$ in the local regulation of platelet vessel wall interaction. However they do suggest that secretion from the lungs or other organs, and subsequent systemic circulation of $\mathrm{PGI}_{2}$ does not represent an important homeostatic mechanism in vivo.

\section{ACKNOWLEDGMENTS}

We are indebted to Ms. M. Schworer for technical assistance and to Mrs. Kathy Tinkham who typed the manuscript.

Supported in part by U. S. Public Health Service grant GM 15432. Prostacyclin sodium was kindly donated by Dr. Joanne Data and Dr. Udo Axen of the Upjohn Co.

\section{REFERENCES}

1. Moncada, S., and J. R. Vane. 1978. Unstable metabolites of arachidonic acid and their role in hemostasis and thrombosis. Br. Med. Bull. 34: 129-135.

2. Gorman, R. R., S. Bunting, and O. V. Miller. 1977. Modulation of human adenylate cyclase by prostacyclin (PGX). Prostaglandins. 13: 377-388.

3. Ferreira, S. H., and J. R. Vane. 1967. Prostaglandins: their disappearance from and release into the circulation. Nature (Lond.). 216: 868-871.

4. Armstrong, J. M., N. Lattimer, S. Moncada, and J. R. Vane. 1978. Comparison of the vasodepressor effects of prostacyclin and 6-oxo-prostaglandin $F_{1 \alpha}$ with those of prostaglandin $\mathrm{E}_{2}$ in rats and rabbits. Br. J. Pharmacol. 62: $125-130$.

5. Gryglewski, R., R. Korbut, and A. Ocetkiewcz. 1978. Generation of prostacyclin by lungs in vivo and its release into the arterial circulation. Nature (Lond.). 273: 765-767.

6. Moncada, S., R. Korbut, S. Bunting, and J. R. Vane. 1978. Prostacyclin is a circulating hormone. Nature (Lond.). 273: 767-768.

7. Gryglewski, R. J., R. Korbut, A. Ocetkiewcz, and T. Stachwa. 1978. In vivo method for quantification of antiplatelet potency of drugs. Nauyn-Schmiedeberg's Arch. Pharmacol. 302: 25-30.

8. Smith, J. S., M. L. Lefer, and K. C. Nicolaou. 1978. Antibodies which antagonize the effects of prostacyclin. Nature (Lond.). 274: 64-65.

9. Steer, M. L., S. E. MacIntyre, L. Levine, and E. W. Salzman. 1980. Is prostacyclin a physiologically important circulating antiplatelet agent? Nature (Lond.). 283: 194-195.
10. Pace-Asciak, C. R., M. C. Carrara, L. Levine, and K. C. Nicolaou. 1980. $\mathrm{PGI}_{2}$ specific antibodies administered in vivo suggest against a role for endogenous $\mathrm{PGI}_{2}$ as a circulating vasodepressor hormone in the normotensive and spontaneously hypertensive rat. Prostaglandins. 20: $1053-1060$.

11. Falardeau, P., J. A. Oates, and A. R. Brash. 1981. Quantitative analysis of two dinor metabolites of prostaglandin $\mathrm{I}_{2}$. Anal. Biochem. In press.

12. Draper, N., and H. Smith. 1966. In Applied Regression Analysis. John Wiley and Sons, Inc., New York, London, and Sydney. pp 44-85.

13. Snedecor, G. W., and W. G. Cochran. 1967. Statistical Methods. Iowa State University Press, Ames, Iowa. pp 135-171.

14. Rosenkranz, B., C. Fischer, K. E. Weimer, and J. C. Frölich. 1980. Metabolism of prostacyclin and 6-ketoprostaglandin $F_{1 \alpha}$ in man. J. Biol. Chem. 255: 1019410198.

15. Rosenkranz, B., C. Fischer, I. Reimann, K. E. Weimer, G. Beck, and J. C. Frölich. 1981. Identification of the major metabolite of prostacyclin and 6-keto prostaglandin $F_{1 \alpha}$ in man. Biochim. Biophys. Acta. 619: 207-213.

16. FitzGerald, G. A., L. A. Friedman, I. Miyamori, J. O'Grady, and P. J. Lewis. 1979. A double blind placebo controlled crossover study of prostacyclin in man. Life Sci. 25: $665-672$.

17. FitzGerald, G. A., J. Watkins, H. T. Dargie, and P. J. Lewis. 1981. Cardiac effects of prostacyclin in man. In The Clinical Pharmacology of Prostacyclin. P. J. Lewis and J. O'Grady, editors. Raven Press, New York and London. pp 145-152.

18. Hensby, C. N., P. Barnes, C. T. Dollery, and H. J. Dargie. 1979. Production of 6-oxo-PGF - $_{1 \alpha}$ by human lung in vivo. Lancet. II: 1162-1163.

19. Masotti, G., L. Puggelesi, G. Pogessi, G. Galanti, F. Trotta, and G. C. Neri Serneri. Prostacyclin production in man. In The Clinical Pharmacology of Prostacyclin. P. J. Lewis and J. O'Grady, editors. Raven Press, London and New York. pp 9-20.

20. Mitchell, M. D. 1978. A sensitive radioimmunoassay for 6-keto-prostaglandin $F_{1 \alpha}$ : preliminary observations on circulating concentrations. Prostaglandins and Medicine. 1: 13-21.

21. Hensby, C. N., G. A. FitzGerald, L. A. Friedman, P. J. Lewis, and C. T. Dollery. 1979. Measurement of 6-oxo$\mathrm{PGF}_{1 \alpha}$ in human plasma using gas chromatography-mass spectrometry. Prostaglandins. 18: 731-735.

22. Claeys, M., C. Van Hove, A. Duchateau, and A. G. Herman. 1980. Quantitative determination of 6-oxo$\mathrm{PGF}_{1 \alpha}$ in biological fluids by gas chromatography mass spectrometry. Biomed. Mass. Spec. 544-548.

23. Myatt, L., M. Jogee, P. J. Lewis, and M. G. Elder. 1981. The metabolism of prostacyclin and 6-oxo-PGF ${ }_{1 \alpha}$ in man. In The Clinical Pharmacology of Prostacyclin. P. J. Lewis and J. O'Grady, editors. Raven Press, London and New York. pp 30-42.

24. Machin, S. J., D. A. F. Chamone, G. Defreyn, and J. Vermylen. The effect of clinical prostacyclin infusions in advanced arterial disease on platelet function and plasma 6-keto-PGF ${ }_{1 \alpha}$ levels. 47: 413-422. 